\section{El discurso del periódico La Nación sobre la participación política de las personas jóvenes en Costa Rica (2009-2014)}

RESUMEN

Este artículo trata de dilucidar las imágenes sobre las personas jóvenes que se encuentran en el contenido de las noticias del periódico La Nación. Para esto, se han recolectado noticias referentes a cuatro coyunturas distintas: las marchas del $1^{\circ}$ de mayo (2009-2014), el movimiento por la "Ley del Fotocopiado" (2012), la implementación de educación sexual en colegios públicos (2013) y la campaña electoral (20132014). Estas coyunturas permiten visualizar las diferencias del discurso de La Nación respecto a la participación de las personas jóvenes, según si esta ocurre en un espacio institucionalizado o no institucionalizado. Asimismo, se pretende identificar los elementos adultocentristas presentes en el discurso de este periódico

\section{Palabras Clave}

Análisis de discurso; participación política; jóvenes; medios; Costa Rica
The Discourse of La Nación Newspaper about the Political Participation of Young People in Costa Rica (2009-2014)

\section{ABStract}

This paper tries to determine the images of the young people that are shown in the articles published in La Nación. For this purpose newspaper articles concerning four different situations were collected. The situations chosen for this study were: the marches of May 1st (2009-2014), Movement for "Photocopying Act" (2012), the implementation of sex education in public high schools (2013) and the national election process (2013-2014). The analysis of the articles led to the visualization of differences in La Nación's discourse regarding the participation of young people. Different discourses found depend on the space -institutionalized or not institutionalized -in which young people participation occurs. The paper also tries to identify adult-centered elements present in the discourse of this newspaper.

\section{KEY WORDS}

Discourse analysis; political participation; youth; media; Costa Rica
Artículo recibido:

17 de octubre del 2015.

Evaluado:

4 de marzo del 2016.

Aceptado:

18 de marzo del 2016.

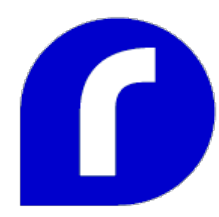

José Andrés Díaz González en Ciencias Políticas y Mágister en Historia. Investigador del Rica (UNA) y docente de la Escuela de Ciencias Políticas de la Universidad de Costa Rica Correo electrónico: joseandres.diaz@ucr.ac.cr 


\section{El discurso del periódico La Nación sobre la participación política de las personas jóvenes en Costa Rica (2009- 2014) *}

* El presente texto expone algunas conclusiones parciales del proyecto de investigación "Culturas políticas y grupos juveniles: análisis de las distintas representaciones de las prácticas políticas de la población joven", realizado en el Programa Umbral Político del Instituto de Estudios Sociales en Población (IDESPO) de la Universidad Nacional de Costa Rica (UNA). El autor desea agradecer los valiosos comentarios $y$ aportes realizados por la Msc. Sindy Mora S., el Lic. Luis Diego Soto K., la Mel. Laura Solís B. y la Bach. Silvia Castillo; no obstante, cualquier error u omisión presente en el artículo es exclusivamente responsabilidad del autor.
El objetivo de este artículo es identificar el discurso adultocentrista, en relación con la práctica política de las persona jóvenes, manifiesto en el discurso informativo de La Nación. Es necesario indicar que el adultocentrismo

...destaca la superioridad de los adultos por sobre las generaciones jóvenes y señala el acceso a ciertos privilegios por el solo hecho de ser adultos. Ser adulto es el modelo ideal de persona por el cual el sujeto puede integrarse, ser productivo y alcanzar el respeto en la sociedad (UNICEF, 2013, p. 18).

Por lo tanto, se busca indicar cómo en este discurso se critica o cuestiona el comportamiento y las actitudes de las personas jóvenes, debido al hecho de no cumplir con los parámetros del comportamiento ideal sustentado por las personas adultas. En contraposición, se espera observar en el discurso mediático cómo se aprueban aquellos comportamientos de las personas jóvenes que sean congruentes con el ideal adultocentrista.

Para lograr lo propuesto, se han recolectado noticias que permitan observar la manera en que el medio informa sobre la participación y acciones de las personas jóvenes en tres espacios diferentes: movimientos sociales, partidos 
políticos y espacios educativos. A partir de ellos se obtienen datos para constatar la siguiente hipótesis: La imagen que proyecta el periódico La Nación sobre las personas jóvenes depende del espacio en que estos participan, así como de la valoración que el propio medio realiza sobre estos espacios, a partir de una postura de adultocentrismo político respecto a la participación de las persona jóvenes; de tal manera que visualizará como positivas las acciones de personas jóvenes en espacios controlados o reglamentados por personas adultas y como negativas las acciones de personas jóvenes en espacios donde no son directamente "supervisadas" por adultos.

La importancia de determinar la imagen proyectada por los medios se debe a que estos construyen el contenido de sus noticias para que respondan a su propia lógica de interpretación de los acontecimientos que reseñan:

El contenido de los medios se puede basar en lo que sucede en el mundo material aunque separa y sólo destaca ciertos elementos, y la propia estructura lógica del medio se impone sobre dichos elementos. La realidad es manipulada necesariamente cuando los sucesos y las personas se vuelven a colocar dentro de noticias transmitidas... Los medios pueden imponer su propia lógica al ensamblar materiales en una serie de maneras, incluyéndose el énfasis de ciertos comportamientos y personas $y$ estereotiparlas... Una de las maneras más obvias en que el contenido de los medios estructura un ambiente simbólico es poniéndole una mayor atención (en la forma de más tiempo, mayor importancia y demás) a ciertos sucesos, personas, grupos y lugares que a otros (Shoemaker y Reese, 1994, p. 38. El resaltado no es original).

No hay que olvidar además que las noticias, como una unidad de información que transmite el medio de comunicación, no solamente se encuentran definidas por el ente emisor, sino también por el receptor (generalmente denominado opinión pública), que tiene interés o encuentra cierto valor de informarse sobre una serie de acontecimientos determinados (McQuail, 1996, p. 372). Por lo tanto, el seguimiento que realiza La Nación sobre diferentes coyunturas y acciones en las que se ven involucradas las personas jóvenes puede también interpretarse como la existencia en un interés de la población costarricense sobre este sector de la población. Además, no hay que obviar 
el hecho de que, si bien los medios de comunicación no le indican a la población cómo pensar, sí pueden influir indicándoles en qué pensar (Busto, 2011, p. 111). En otras palabras, los medios pueden desarrollar una agenda propia con el propósito de colocar la atención de la opinión pública sobre determinados temas, al mismo tiempo que se ignoran otros (Villalobos, 2000, p. 88), y con ello tratar de influir en la manera en que la opinión pública valora e interpreta las distintas formas de participación de la población joven.

Por último, la selección de La Nación para realizar este análisis se debe, primero, a que puede ser identificado como uno de los medios de comunicación costarricense que mantiene fuertes relaciones con los sectores empresariales, por lo que tiene una amplia capacidad de presión sobre el escenario y las decisiones políticas adoptadas en el país (Murillo, 2010; Robles y Voorend, 2012). Segundo, ya en otras investigaciones se ha demostrado que en el discurso informativo de La Nación se tiende a visualizar los espacios institucionalizados como positivos, mientras que los espacios no institucionalizados donde participan distintos grupos de la ciudadanía son descritos de forma negativa (Díaz, 2012a y 2013). Por lo tanto, se espera observar si esta tendencia en el discurso del medio se reproduce y afecta la manera en que informan a la opinión pública sobre distintas actividades políticas en las que participan las personas jóvenes.

\section{Aspectos teóricos y metodológicos}

En la sociedad globalizada actual los medios juegan un papel de gran importancia al generar y emitir información sobre hechos diferentes ocurridos en la propia sociedad, con el propósito de que los individuos los conozcan y en el mejor de los casos- se formen un criterio que les permita tomar una posición respecto a estos. Para comprender el impacto de los discursos informativos (noticias y reportajes periodísticos), Teun van Dijk (2005) indica que es necesario emplear una perspectiva interdisciplinaria que permita descubrir las incógnitas de dichos discursos, aplicando no solo las teorías y herramientas tradicionales del análisis de discurso, sino también el estudio de los contextos específicos en el que dichos discursos informativos son creados y transmitidos.

De esta manera, el análisis de los discursos informativos permite determinar qué ideología están pretendiendo transmitir los medios (en nuestro caso, sobre las personas jóvenes y su participación en distintos espacios sociales) hacia la sociedad. Se puede entender las ideologías como creencias fundamentales que subyacen en las representaciones sociales compartidas por tipos específicos de grupos sociales. Estas representaciones son a su vez la base del discurso y de otras prácticas sociales. Asimismo, se parte del 
supuesto de que las ideologías son principalmente expresadas y adquiridas a través del discurso, esto es, por interacción comunicativa hablada o escrita (van Dijk, 2005, p. 15). Asimismo, Vásquez (2011, pp. 10-12) indica que el estudio de las narrativas de los medios permite identificar cómo estos construyen y reproducen estigmas y estereotipos sobre las personas jóvenes, los cuales funcionan como elementos simbólicos que la sociedad utilizará para evaluar e interpretar el accionar de este grupo.

Es necesario indicar que el discurso se puede entender como "una práctica social (...) una forma de acción entre la personas que se articulan a partir del uso lingüístico contextualizado, ya sea oral o escrito" (Casimiglia y Tusón, 1999, p. 15. El resaltado es original). Por su parte, Teun van Dijk, al referirse a discurso como práctica social, manifiesta que "la utilización discursiva del lenguaje no consiste solamente en una serie ordenada de palabras, cláusulas, oraciones y proposiciones, sino también en secuencias de actos mutuamente relacionados" (van Dijk, 2000, p. 21).

Para realizar el análisis de los discursos informativos y, por ende, conocer el discurso manifiesto en ellos, es necesario considerar cuál es el contexto y el modelo del texto. En cuanto al contexto, van Dijk (2005) expresa que el uso del idioma, en general, y la producción del discurso y comprensión, en particular, dependen e influyen en las propiedades relevantes de la situación comunicativa, tal como son interpretadas por los usuarios del idioma. Estas "definiciones de la situación" de carácter subjetivo o "contextos" son representados como modelos específicos en la memoria episódica: son los denominados modelos de contexto (van Dijk, 1999). Estos modelos de contexto controlan muchos aspectos del proceso de discurso y aseguran que un discurso sea socialmente apropiado. Como es el caso para todos los modelos mentales subjetivos, los modelos de contexto pueden corresponder ideológicamente a "prejuicios", como resultado de actitudes subyacentes que son, de por sí, ideológicas. Así, para el presente artículo se seleccionaron noticias referentes a cuatro contextos diferentes: la participación en la campaña electoral (2013-2014), la implementación de educación sexual en colegios públicos (2013), las marchas del $1^{\circ}$ de mayo (2009-2014) y el movimiento por la "Ley del Fotocopiado" (2012) (ver tabla 1).

La elección de las coyunturas mencionadas se realizó con la intención de seleccionar noticias que visualizaran la participación de las personas jóvenes en espacios institucionalizados y no institucionalizados; es decir, en donde directamente se encontraran supervisados por estructuras y personas "adultas" (campaña electoral e implementación de educación sexual en colegios públicos), y en donde actuaran fuera del control adultocéntrico (marchas del $1^{\circ}$ de mayo y el movimiento por la "Ley del Fotocopiado"). Como se menciona anteriormente, en otros trabajos se ha determinado la preferencia en el discurso de La Nación por la utilización de espacios institucionalizados para la solución de conflictos sobre las acciones 
realizadas en espacios no institucionalizados (Díaz, 2012a y 2013); por lo tanto, con esta selección se pretende observar cómo esta preferencia del medio impacta en su discurso sobre las personas jóvenes.

\section{Tabla 1}

Breve descripción de los contextos de las noticias recolectadas sobre la participación de las personas jóvenes, publicadas por La Nación. Costa Rica, 2009-2014.

Contexto Descripción

Todos los $1^{\circ}$ de mayo se lleva a cabo la llamada "Marcha del día Internacional de trabajo", en la cual participan sindicatos,

$1^{\circ}$ de mayo

(2009-2014) organizaciones de la sociedad social civil, entre otros. Desde el 2009, la participación de grupos de jóvenes ha sido más visible en este espacio, debido en parte a los enfrentamientos que han mantenido las autoridades de policía con un sector de los jóvenes que participan en dichas marchas.

Tras la aprobación del TLC con los Estados Unidos (CAFTADR), se aprobó la llamada "agenda de implementación", un conjunto de leyes de objetivos varios, entre ellos la protección de la propiedad intelectual y la instauración de multas y penas Movimiento por la de cárcel para aquellas personas que las transgredieran. "Ley del fur Fotocopiado" (2012) Debido a ello, se crea un movimiento de estudiantes, el cual fue denominado "Fotocopiando para Estudiar". Este grupo de estudiantes se encontraba preocupado sobre cómo dicha legislación podría afectar el fotocopiar material con fines educativos, perjudicando así el derecho a la educación. Esto lleva a la Asamblea Legislativa a aprobar la llamada "Ley del Fotocopiado", la que posteriormente es vetada por la entonces presidenta de la República, Laura Chinchilla Miranda.

Implementación de A partir del 2013, el Ministerio de Educación Pública educación sexual implementó una serie de cursos sobre educación sexual en los en colegios colegios públicos. Este accionar encontró la oposición de las públicos iglesias católicas y evangélicas. (2013)

Entre octubre del 2013 y febrero del 2014 se desarrolló la campaña electoral para la elecciones nacionales del 2014. En este proceso electoral se eligen las personas que ocuparán la Presidencia y las Vicepresidencias de la República, así como a los y las miembros de la Asamblea Legislativa.

Campaña electoral (2013-2014)

Fuente: Elaboración propia.

Lo anterior lleva a la necesidad de abordar el estudio de los discursos periodísticos o informativos desde la perspectiva del Análisis Crítico del Discurso (ACD), un enfoque particular del análisis del discurso que se centra 
en los problemas sociales, a partir tanto del contexto como de elementos lingüísticos y semióticos. Murillo Medrano y Vergara Heidke (2004, p. 205) indican que la posición crítica del ACD debe entenderse como el resultado de tomar cierta distancia respecto de los datos, enmarcando estos en lo social, al mismo tiempo que se adopta una postura política y se centra en la autocrítica.

Asimismo, en el ACD el lenguaje es considerado como un instrumento de dominación, el cual legitima las relaciones de poder debido a su carácter ideológico, ya que "expresa el poder, moldea el poder y desafía al poder"; por lo tanto, existe una relación dialéctica entre el lenguaje y el poder, ya que el discurso (lenguaje) constituye al poder contribuyendo a la formación y reproducción del statu quo social, a la vez que el discurso es constituido por el poder, el cual determina su actualización (Murillo y Vergara, 2004, pp. 205206).

De esta manera, el ACD corresponde a un enfoque interdisciplinario dentro del análisis del discurso, el cual

Se ocupa de problemas sociales -como las relaciones de poder, dominación y desigualdad-, con el fin de descubrir, revelar las ideologías que reproducen o resisten al poder, por medio de una multiteoría y multimetodología, tomando una postura política explícita y una perspectiva tanto crítica como autocrítica (Murillo y Vergara, 2004, p.207).

Así, el ACD busca determinar cómo se utiliza el lenguaje para construir la "realidad" o percepción de los sujetos de la realidad, así como la forma en que estos la transmiten en su afán de lograr un consenso con los demás integrantes de la sociedad.

Es conveniente recordar que la información recopilada corresponde únicamente a noticias y no incluye los editoriales ni los artículos de opinión 1. La recopilación de las publicados durante ese periodo por La Nación relacionados con los temas noticias fue llevada a cabo por seleccionados ${ }^{1}$ Esto debido a que lo que se busca es observar cómo este el Bach. Vinicio Vargas, seleccionados. ${ }^{1}$ Esto debido a que lo que se busca es observar cómo este asistente del Programa de medio presenta la información referente a cada caso, por lo que utilizar los Investigación Umbral Político artículos de opinión publicados por este periódico provocaría que se (UNA). Se desea dejar analizara analizara el contenido de posiciones que no necesariamente corresponden a por su valiosa colaboración la visión del medio. En el cuadro 1 se puede visualizar la cantidad de noticias para la realización de este recopiladas para cada caso. 
Cuadro 1

Cantidad de noticias publicadas por La Nación en los casos seleccionados. Costa Rica, 2009-2014.

\begin{tabular}{|l|c|}
\hline \multicolumn{1}{|c|}{ Caso } & Cantidad de Noticias \\
\hline $1^{\circ}$ de mayo (2009-2014) & 8 \\
\hline Movimiento por la "Ley del Fotocopiado" (2012) & 8 \\
\hline $\begin{array}{l}\text { Implementación de educación sexual en colegios públicos } \\
(2013)\end{array}$ & 6 \\
\hline Campaña electoral (2013-2014) & 2 \\
\hline
\end{tabular}

Fuente: Elaboración propia.

Por último, es necesario indicar que, si bien se recolectan todas las noticias publicadas por el periódico La Nación de las coyunturas anteriormente señaladas, estas deben considerarse una muestra de todas las noticias publicadas por este medio en relación con las persona jóvenes. De esta manera, el análisis de discurso que se realiza en el presente texto corresponde únicamente al contenido de dichas noticias. A pesar de esto, se puede partir del supuesto de que el discurso mostrado en las noticias analizadas es reproducido en otras notas publicadas por La Nación con respecto a las personas jóvenes; esto debido a que los periódicos tienden a tener una línea editorial que sirve como base para el estilo de redacción, así como para el enfoque que da a las noticias.

\section{La imagen de las personas jóvenes en los movimientos sociales}

En este apartado se analiza el contenido de las noticias publicadas por La Nación en relación con las manifestaciones realizadas durante el $1^{\circ}$ de mayo (2009-2014) y el movimiento en favor de la aprobación de la "Ley del Fotocopiado" (ver Tabla 1). Ambos casos se tratan de acciones que las personas jóvenes realizan en el marco de movimientos sociales. En el caso del $1^{\circ}$ de mayo, las noticias hacen referencia a eventos ocurridos en las marchas llevadas a cabo entre el 2009 y el 2014; sin embargo, lo que se busca es identificar la imagen general que transmite el medio sobre los y las jóvenes que se ven involucrados en enfrentamientos con las autoridades de policía. En el caso del movimiento por la "Ley del Fotocopiado", las noticias estudiadas informan sobre distintas acciones, en especial una manifestación frente a la Asamblea Legislativa acaecida en octubre del 2012, llevada a cabo por las personas jóvenes para impulsar la aprobación de la ley y combatir el veto a esta realizado por la entonces presidenta de la República, Laura Chinchilla Miranda. 
La participación de las personas jóvenes en movimientos sociales es valorada de manera negativa por La Nación, ya que este medio pone énfasis en sus noticias a los daños y problemas que estos jóvenes ocasionan en sus acciones de protesta e invisibiliza sus razones y motivos para protestar. Así, las personas jóvenes que participan en las manifestaciones del $1^{\circ}$ de mayo del 2013, en el contenido de La Nación, son prioritariamente visualizados como "anarquistas" y se indica que son los responsables directos de las perturbaciones del orden y los actos violentos que acontecen en estas manifestaciones:

Los muchachos que generaron los disturbios el $1 .^{\circ}$ de mayo [del 2013] se llaman anarquistas o ingobernables. El grupo está formado por cerca de 35 a 40 personas, que se caracterizan por vestir ropa negra y cubrir los rostros con pañuelos del mismo color (Arguedas y Láscarez, 2013).

Un aspecto interesante es que, para La Nación, parece ser conflictiva la "estética" o forma de vestir de estos jóvenes, ya que transgrede lo que parece considerar como "buenas costumbres". Esto se debe a que se cubren su rostro, señal que el medio interpreta como una forma que utilizan los jóvenes para no ser reconocidos y realizar actos violentos. Al respecto, para el caso del $1^{\circ}$ de mayo del 2013, este medio expresa:

Asimismo, se aportaron pañuelos negros con los que se cubrían los rostros y mensajes escritos en papeles y que están pegados a las botellas con gasolina donde mencionan entre otras las palabras "resistencia y revolución". "Estas personas tienen un nivel de agresión que viene creciendo. En la Asamblea lanzaron esas bombas no solo contra la Policía sino contra la población civil rayando casi en un nivel de terrorismo. Lo que pretendían era generar caos", manifestó Gamboa (Arguedas y Láscares, 2013).

Sobre este aspecto, Sibaja Quesada (2009) expone que las personas jóvenes utilizan su cuerpo, forma de vestir, accesorios, música y destreza para poder visualizarse en una sociedad adultocéntrica que tiende a marginalizarlos y no tomarlos en cuenta en los espacios sociales y políticos. De esta manera, la vestimenta de estos jóvenes "anarquistas" respondería a una estrategia política para hacer visible su actuación y demandas. De esta manera, al condenar su forma de vestir y no sus consignas y demandas 
políticas, se puede inferir que a La Nación le molesta que un grupo de personas jóvenes logre resaltar para llamar la atención de la opinión pública.

Según la narrativa de este periódico, estos jóvenes actúan sin motivación aparente, ya que en el contenido de las noticias nunca se entrevista a estas personas o se trata de exponer las razones detrás de su comportamiento (Herrera, 2012). Asimismo, este medio indica que estos jóvenes atacan o perjudican a los otros actores con los que participan de manera conjunta en la marcha del $1^{\circ}$ de mayo del 2009 :

Por casi media hora, los jóvenes (que marcharon por San José al frente de los sindicalistas) no cesaron de insultar al gobierno, a la policía, a la prensa y pintar graffitis sobre una pared del Museo Nacional localizada frente al Congreso. Incluso cerraron el paso a una de las tumbacocos de los sindicatos.

La situación obligó a los organizadores de la marcha a desistir de cantar el Himno Nacional y realizar el discurso de cierre, a cargo del dirigente Luis Salas Sarkis en nombre de la Coordinadora Sindical, Magisterial y Comunal (Cusima) (Lara, 2009).

Asimismo, La Nación informa que miembros de la prensa son atacados por estos jóvenes en las manifestaciones llevadas a cabo durante el Día del Trabajo, en el 2009 y 2013, sin motivo alguno aparente (Lara, 2009; Láscares, 2013). De esta manera, queda clara la intención del medio de indicar que estos jóvenes son agresivos e incluso constituyen una amenaza para el presidente estadounidense, Barack Obama, quién se encontraba de visita en Costa Rica en el 2013:

Los autodenominados "anarquistas" empezaron su acto con la quema de un afiche del presidente Barack Obama y de una bandera de Estados Unidos, al mismo tiempo que agitaban las vallas de seguridad y las golpeaban con patadas y palos.

"Nosotros les pagamos sus salarios y nos vamos a manifestar igual contra Obama", amenazaba el grupo a los oficiales 
que resguardaban el perímetro del Congreso (Barrantes y Arguedas, 2013).

Según La Nación, el grado de agresividad manifestado por este grupo justifica las represión y la violencia que la policía ejerce en su contra para mantener e instaurar el orden. Así, para este medio, la actuación de la "autoridad" se concentra en controlar el conflicto generado por los anarquistas; no obstante, esto no evita que sean víctimas de este grupo:

Un destacamento de antimotines llegó después de varias provocaciones, en las que los "anarquistas" lanzaron piedras, botellas de vidrio y palos a las mujeres policías que estaban detrás de las vallas.

La situación quedó controlada cuando las autoridades detuvieron a doce miembros de este grupo que golpearon a seis efectivos de la Fuerza Pública, dos de los cuales fueron trasladados a hospitales (Barrantes y Arguedas, 2013).

Además, en el contenido de las noticias se menciona constantemente los daños que realizan este grupo de jóvenes, pero no menciona que estos sufran ningún daño o hayan sido también víctimas de actos de violencia. Con esto, La Nación refuerza la idea de que los "anarquistas" son los responsables de los actos de violencia ocurridos durante las manifestaciones del $1^{\circ}$ de mayo, calificando sus acciones como "vandalismo" (Lara, 2009).

Lo anterior puede observarse como una estrategia para invisiblizar el contenido político detrás de las acciones de este grupo de jóvenes, evitando entonces que la opinión pública se percate del mensaje político que desean transmitir, así como de las razones de su descontento. Otro punto que refuerza esta idea es que las noticias publicadas sobre las acciones de este grupo "anarquista" se realizan en la sección de Sucesos y no en la de Política. Como Carlos Villalobos (2000) indica, el periódico, al dividir la información que transmite en secciones, genera expectativas en la persona lectora sobre el contenido que encontrará en estas y con ello incide en la forma en que dará lectura e interpretará la información. Por lo tanto, al colocarse estas noticias en la sección de Sucesos, las personas que lean dichas noticias no estarán esperando relacionar el contenido de estas con un fondo político, sino con actos más cercanos al vandalismo y a los crímenes que el diario suele reportar en esta sección. 
Una situación similar ocurre con los jóvenes que participan en el movimiento a favor de la "Ley para el Fotocopiado", ya que en las referencias hechas sobre este grupo en las noticias publicadas hay una clara tendencia de ligarlos a acciones "conflictivas" o negativas: "La marcha de jóvenes en contra del veto presidencial a la ley de fotocopiado terminó en un zafarrancho, cuando un grupo se enfrentó a golpes y pedradas con la policía, en las afueras de la Asamblea Legislativa" (Oviedo y Cerdas, 2012).

Asimismo, estas personas jóvenes son presentadas como un grupo amorfo, sin ningún tipo de organización o dirección y, aunque son un actor principal en la narrativa de los acontecimientos, el periódico no informa sobre sus opiniones o criterios. Tampoco le interesa mostrar a los lectores que este se trata de un movimiento diverso y, por ende, está conformado por distintos grupos que tienen diversas reacciones, las cuales no necesariamente son compartidas por los otros grupos que se engloban en este movimiento. Incluso, a pesar del esfuerzo de los y las manifestantes en contra del veto a la "Ley de Fotocopiado" de diferenciarse del grupo que realizó acciones violentas durante la protesta, La Nación se esfuerza por vincularlos:

A pesar de que este grupo, supuestamente, no pertenecía a los universitarios que marcharon en contra del veto presidencial a la ley de fotocopiado, estos se identificaron como 'estudiantes $y$ ciudadanos'.

Hoy, a las 2:15 p.m., un grupo de 20 personas se apostaron en el costado sur del complejo legislativo sentados en las rejas del edificio. Unos 600 manifestantes se establecieron en la avenida central, apoyando las acciones de sus compañeros que ingresaron al edificio (Mata y Altamirano, 2012).

Además, es llamativo el uso del entrecomillado, en el texto anterior, para hacer referencia a la identificación de las personas jóvenes como estudiantes y ciudadanos. Al entrecomillar estas palabras, La Nación está sugiriendo al lector que esta no es la forma correcta de identificar a este grupo de personas. Así, al quitarles su identificación como estudiantes, buscan deslegitimar su reclamo como parte de su defensa al derecho a la educación $y$, al quitarle su condición de ciudadanos, les niega los derechos que esta categoría les infiere.

Esta tendencia de La Nación de visualizar de esta forma a las personas jóvenes, en especial a los y las estudiantes de universidades públicas, no es nueva. Esta estrategia discursiva puede encontrarse en noticias relacionadas 
con otras coyunturas donde aparecen como actores relevantes (Díaz, 2012a). Además, como ha demostrado Carballo Chaves (2009), el discurso mediático de La Nación sobre el sector educativo público costarricense tiende a realizar una sobre exposición de los temas negativos que afectan $u$ ocurren en este, al mismo tiempo que invisibiliza o minimiza la participación y aportes de dicho sector.

Por lo tanto, para La Nación es necesario sancionar a los jóvenes cuyo comportamiento causa "desorden", de forma que se hace necesario en su discurso la figura de un agente supervisor (un adulto) que tome las acciones necesarias para controlar a las personas jóvenes. De esta manera, las distintas autoridades de gobierno son los entes encargados de tratar de detener el "desorden" ocasionado por las personas jóvenes, así como de realizar las investigaciones necesarias para castigar dichas acciones:

El Ministerio de Seguridad Pública denunció a unos 11 sujetos por los disturbios ocasionados este martes frente al edificio de la Asamblea Legislativa, tras la marcha contra el veto de la ley de fotocopiado.

El viceministro de Seguridad, Celso Gamboa, entregó esta mañana la denuncia, ante el OIJ, por delitos de resistencia a la Fuerza Pública, lesiones a los agentes y daños a la propiedad privada, así como, al edifico de la Asamblea Legislativa (Cuesta, 2012).

Además, las fotografías utilizadas por el medio para ilustrar estas noticias muestran a las autoridades de policía en actitud "defensiva" mientras reciben "ataques" provenientes de las personas jóvenes (ver Imagen 1). Esto puede ayudar a promover ante la opinión pública la idea de que la policía tuvo que reaccionar ante la violencia que sufrió por parte de los y las manifestantes, invisibilizando o a minimizando la violencia sufrida por estos últimos en manos de los cuerpos policiales: "En la calle, al costado sur de la Asamblea, los estudiantes la emprendieron contra los policías quienes respondieron a los jóvenes con escudos y macanas" (Oviedo y Cerdas, 2012).

Asimismo, este medio indica que los diputados y diputadas son objeto de los ataques de las personas jóvenes, a pesar que estos fueron los que aprobaron la "Ley del Fotocopiado". Así, a La Nación le interesa posicionar ante la opinión pública el "ataque" de que es objeto el diputado Claudio Monge, uno de los propulsores de la ley, el cual "(...) acabó mojado de orines luego de que una bolsa estallara cerca suyo cuando trató de mediar 
para sacar a una veintena de muchachos que se apoderó de la entrada del edificio central" (Mata y Altamirano, 2012. El resaltado no es original). Con lo anterior se constata que el medio busca construir una narrativa en que las personas jóvenes confrontan y dañan incluso a aquellos actores que buscan apoyarlos en sus demandas.

\section{Imagen 1}

Policía enfrentado a manifestantes. Fotografía publicada por La Nación. Costa Rica, octubre del 2012.

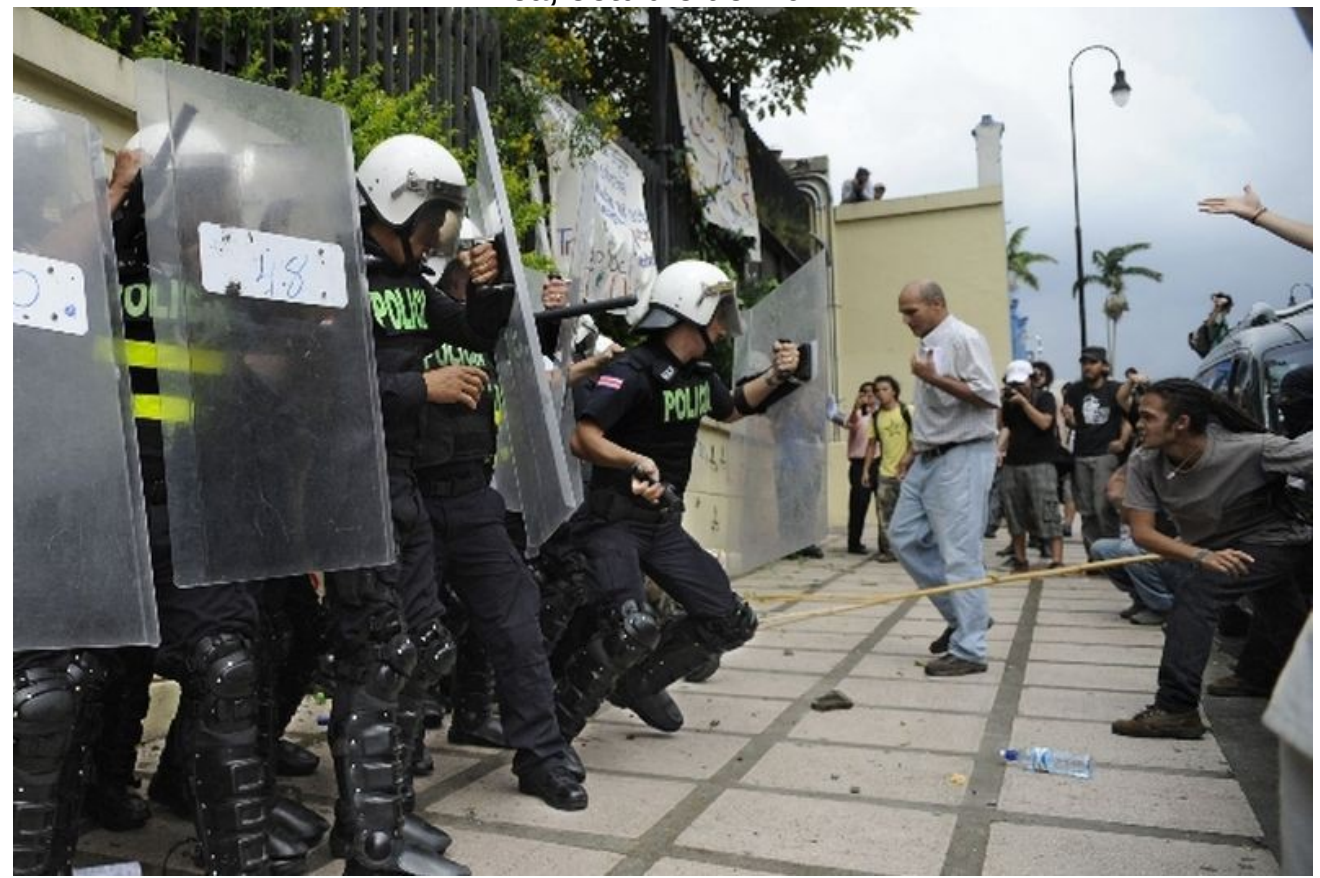

Fuente: Tenorio, A. Publicado en Mata, E. y Altamirano, P. (9 de octubre de 2012).

Un dato adicional que permite observar cómo La Nación desea hacer especial énfasis -ante la opinión pública- en el "daño" ocasionado por las personas manifestantes es la fotografía con la que acompaña uno de sus reportajes (ver imagen 2), en la cual se observa un automóvil con el parabrisas trasero totalmente destruido. A pesar de que en la noticia se reporta que hubieron daños a vehículos (Cuesta, 2012), esta fotografía no corresponde a los hechos descritos sino que es una foto de archivo, es decir, no representa necesariamente la magnitud de los daños ocasionados, sino que fue seleccionada para dar énfasis a la idea del "daño" ocasionado por las personas manifestantes. 


\section{Imagen 2}

Fotografía utilizada por La Nación para ilustrar los "daños" ocasionados por las personas manifestantes. Octubre, 2012.

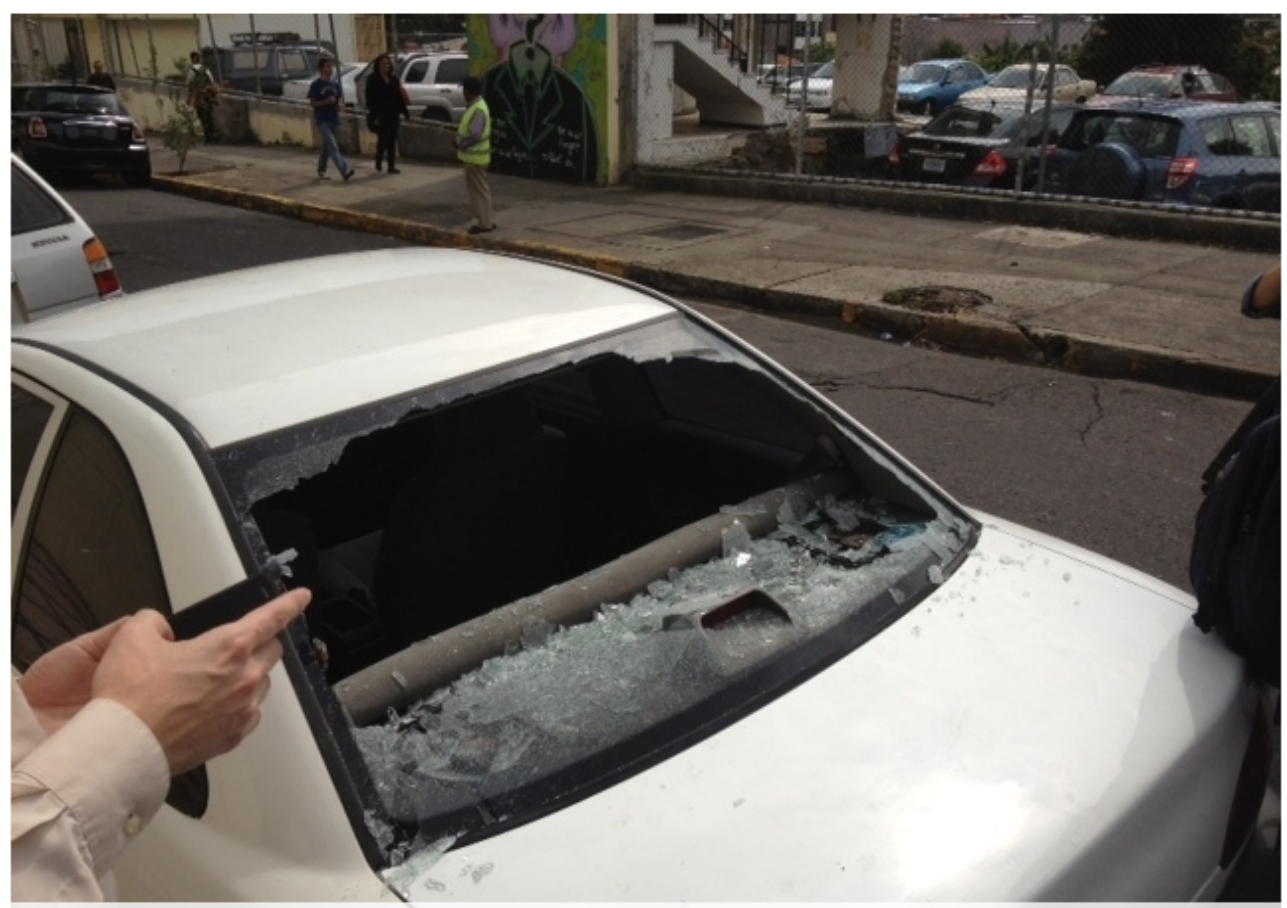

Los sujetos lanzaron piedras luego de la marcha, de este martes, y quebraron parabrisas de vehículos. | ARCHIVO.

Fuente: Cuesta, M. (11 de octubre de 2012).

En cuanto a los actos de violencia cometidos durante la manifestación, La Nación proporciona la imagen de que estos fueron iniciados por las personas jóvenes sin que haya habido ningún tipo de provocación o acto que los incitara (Oviedo y Cerdas, 2012). Por otra parte, la violencia cometida por parte de la policía es, de nuevo, completamente justificada por el medio ya que, según su parecer, era necesaria para poner un orden en dicha situación: "En el segundo choque, los policías detuvieron a un manifestante mientras recibían ataques con piedras. Al detenido, los oficiales le propinaron bastonazos para someterlo" (Oviedo y Cerdas, 2012. El resaltado no es original). Como se aprecia en este breve texto, los periodistas que redactan la nota no expresan ningún tipo de molestia o alarma porque un grupo de policías agrediera a una única persona, a pesar de que ya se encontraba detenida, pues este acto es visto como la forma de "someterlo" y, con ello, controlar la situación. Por lo tanto, se pude inferir que el medio no condena en sí mismos los actos de violencia que ocurrieron durante la manifestación e, incluso, observa la violencia como un mecanismo justificado para controlar a los manifestantes. 
Asimismo La Nación, en el caso de las manifestaciones por la "Ley del Fotocopiado", solo reporta como víctima de actos de violencia al diputado Claudio Monge, quién "terminó bañado en orines", y a los policías que participaron en el altercado: "(...) ocho agentes de la Fuerza Pública permanecen incapacitados porque sufrieron lesiones en el altercado, donde algunos sujetos lanzaron piedras contra la policía" (Cuesta, 2012). En ningún momento en las noticias se informa que algún manifestante recibiera daño alguno, esto a pesar de que el propio medio constata que fueron golpeados por las fuerzas policiales (Mata, 2012; Oviedo y Cerdas, 2012). De esta manera, hay una completa invisibilización de los daños que el grupo de manifestantes pudo haber recibido debido al accionar policial. Esto puede ayudar a posicionar ante la opinión pública la visión de los cuerpos policiales como "víctimas", y con ello ayudar a justificar el uso de violencia por parte de estos hacia las personas manifestantes.

Incluso, La Nación parece compartir la explicación del Poder Ejecutivo acerca de que esta situación de "incertidumbre" -sobre si es legal o no realizar fotocopias de material protegido- es culpa de los y las estudiantes, quienes han "atrasado" la firma de un decreto de ley por parte del Gobierno, el cual supuestamente- vendría a aclarar la situación de las fotocopias para fines académicos. Esto debido a que el movimiento tenía dudas en la redacción e interpretación de varios artículos de dicho decreto (Murillo, 2012). De esta manera, las personas jóvenes son señaladas en la narrativa de La Nación como culpables de una situación que no provocaron ni, de forma alguna, son responsables. Asimismo, este medio hace eco de la apreciación de las autoridades del Poder Ejecutivo sobre la impredecibilidad de la actuación de las personas estudiantes involucradas en la situación:

Ferraro dio ayer dos días más al movimiento estudiantil llamado "Fotocopiando para estudiar", pero no sabe qué respuesta darán ni cómo reaccionará en caso de que se opongan al texto borrador, ya aceptado por el resto de las partes, según Fernando Ferraro (Murillo, 2012).

Del texto anterior se pueden inferir dos apreciaciones. La primera consiste en que las autoridades no pueden predecir o estimar cuál será la respuesta que estos jóvenes darán; en otras palabras, no hay forma de saber en qué están pensando, por qué lo están haciendo y, al mismo tiempo, posiblemente se considere que no tienen la capacidad de dar una respuesta que estos consideren "adecuada" a la situación. La segunda inferencia es que, si bien no se indica de forma explícita, parece que las autoridades "temen" que este grupo de estudiantes reaccione de forma "violenta", tal y como actuó un grupo durante la protesta realizada frente a la Asamblea Legislativa. En otras palabras, las autoridades del Poder Ejecutivo toman el rol de un adulto 
"preocupado y responsable", el cual cuestiona que un "joven" no tenga la capacidad de reaccionar de forma no violenta ante un problema o situación.

\section{La imagen de las personas jóvenes en espacios instituidos}

En este apartado se analizan las noticias publicadas por La Nación referentes a la participación de las personas jóvenes en la implementación de las clases de educación sexual en colegios públicos (en el 2013) y su participación en la campaña electoral 2013-2014. En cuanto al primer caso, las noticias informan sobre la implementación de los programas de educación sexual, la recepción que tuvieron estos entre la población estudiantil y las reacciones que provocó en diversos sectores de las iglesias católica y evangélicas. En el segundo caso, las noticias estudiadas hacen referencia a las actividades que realizan y los puestos que ocupan las personas jóvenes durante la campaña electoral ocurrida entre el 2013 y el 2014.

A diferencia de las personas jóvenes que participan en movimientos sociales, aquellas que lo hacen en espacios institucionalizados y supervisados por personas adultas son valoradas de manera positiva por La Nación. Ya en otra oportunidad había determinado la preferencia expresada en el contenido de las noticias de La Nación de visualizar como positivos los espacios formales de solución de conflictos y participación ciudadana y, en contraposición, presentar como negativos los espacios informales (Díaz, 2012b y 2014). Esta tendencia no solo continúa observándose en las noticias analizadas en el presente texto si no que, además, esta preferencia parece transmitirse a la valoración que el medio realiza sobre las personas jóvenes que participan en estos espacios.

En cuanto la participación en la campaña electoral, La Nación describe a los y las jóvenes que participan en dicho espacio como "muy jóvenes", quienes iniciaron su participación política en los gobiernos escolares y colegiales, y son estudiantes en la mayoría de los casos de universidades públicas, especialmente de la Universidad de Costa Rica (UCR). En este último punto parece haber un énfasis por parte de este medio en indicar que estas personas jóvenes que participan en la política partidaria no han ingresado al mercado de trabajo y aún viven con sus padres (Mata, 2014); con esto podría estar transmitiendo la imagen de que aún no son personas "independientes" ni cuentan con experiencia más allá de la adquirida por la participación en partidos políticos.

La Nación indica que en muchos de los casos las personas jóvenes se incorporan al partido político por un asunto de tradición familiar, hecho que el medio destaca que ocurre más en la juventud del Partido Liberación Nacional (PLN): 
[La participación política de los jóvenes] tiene que ver con una tradición familiar, es decir, se reproduce lo aprendido en la casa. Esto es común en simpatizantes de partidos más antiguos como el PUSC y el PLN. De hecho, en la Juventud Liberacionista, hay nietos de combatientes de la guerra del 48 (Mata, 2014).

Además, apunta que las personas jóvenes que participan en política son vistas de manera sospechosa o con desconfianza; incluso, la introducción de unos de los artículos publicados por La Nación inicia de la siguiente forma: "Les Ilaman 'jala sánguches', chancletudos y corruptos en potencia. Les resienten que estén metidos en política, una palabra que genera desde apatía hasta odio. Pese a ello, estos jóvenes dicen estar claros en sus ideales y comprometidos con su trabajo" (Mata, 2014).

Asimismo, hay un interés de indicar que es diferente el tipo de accionar de estos jóvenes de otros que participan en espacios políticos no formales; incluso los propios jóvenes entrevistados buscan diferenciarse de los jóvenes que tienen una "imagen negativa" ante la sociedad:

"No asistimos a marchas encapuchados ni tiramos piedras.

Participamos en manifestaciones que nos parecen justas y tratamos

de incidir en la actividad para que se desarrolle de forma responsable", detalla Calderón cuando se le pregunta sobre el estereotipo que existe en algunos sectores sobre los frenteamplistas

(Mata, 2014).

Es necesario anotar que La Nación solo hace referencia a la participación de personas jóvenes en los cinco partidos políticos con mayor intención de voto: Liberación Nacional, Frente Amplio, Acción Ciudadana, Movimiento Libertario y Unidad Social Cristiana. Con lo anterior se está invisibilizando la participación de personas jóvenes en otras agrupaciones políticas. Este sesgo de la invisibilización incide en la "alerta" que realiza el medio sobre la disminución de candidatos y candidatas jóvenes a puestos de elección popular, ya que solo toma en consideración a los partidos anteriormente señalados (Mata, 2014b), con lo cual no se informa sobre los candidatos y candidatas en otras agrupaciones que incluso podrían contar con mayor cantidad de personas jóvenes en sus papeletas.

Además, La Nación explica la falta de participación de las personas jóvenes en las estructuras de los partidos políticos debido a la "apatía" que sufre este grupo hacia la política y no considera que las propias estructuras de los 
partidos políticos, o sus acciones y propuestas, pudieran resultar poco atractivas o eviten a las personas jóvenes su incorporación a estos grupos (Mata, 2014b). Siguiendo lo anterior, no es interés de La Nación informar sobre propuestas o proyectos que los partidos políticos pudieran desarrollar en beneficio de la población joven costarricense, con lo cual podría entenderse que la única forma de observar que se desarrollen políticas en favor de este grupo es teniendo personas jóvenes en los puestos de elección popular.

Sobre las actividades que las personas jóvenes realizan durante la campaña electoral, si bien algunas de las personas jóvenes entrevistadas tratan de desligarse de visiones tradicionales o peyorativas, como ser "pegabanderas", en otros casos las personas entrevistadas indican estar a gusto y orgullosos de realizar dichas actividades, ya que las visualizan como algo necesario para el funcionamiento del partido:

El PLN es un partido de bases, está en todos los rincones. Quien nunca ha pegado una bandera no puede llamarse liberacionista. El problema es cuando al 'pegabanderismo' lo censuran y lo catalogan como servilismo. En la Juventud, hacemos muchas cosas más (...).

Chaves opina que hay un aporte importante de la juventud en los temas económicos, así como en la colocación de signos externos: "Pegar banderas o llevar los sánguches se ve como algo negativo, pero alguien tiene que hacerlo. Es un aporte importante, lo que debería preocupar es si a esa persona se le limita solo a eso, porque debería hacer algo más, ir escalando en el partido", dijo (Mata, 2014).

Un elemento interesante en el texto anterior es que se puede inferir que el joven entrevistado reconoce que el lugar de las personas jóvenes en los partidos políticos es, por defecto, el más bajo en la estructura. A partir de ahí debe ir "escalando" a posiciones superiores dentro de la organización. Por lo tanto, el discurso reconoce como algo natural la posición de subordinación de los y las jóvenes dentro de las organizaciones partidarias.

Por último, La Nación plantea el tema de que si participar en la juventud de los partidos políticos es parte de un proceso para ocupar en un futuro cargos públicos. Si bien muchas de las personas jóvenes que se entrevistan indican que no es ese su interés, o no al menos de forma inmediata, otros manifiestan abiertamente que esa es su intención y además expresan 
conocer que es necesario contar con el apoyo de líderes o figuras de la juventud que pueden convertirse en un futuro en importantes miembros del partido:

"Si la pregunta es que si quiero aspirar a puesto de elección popular, no; en este momento no es mi aspiración, pero yo sí veo a Juan Diego diputado, es un gran líder", dice Eduardo en referencia al representante del directorio de la Juventud, Juan Diego Gómez (...).

"Estoy aquí por los principios, por la ideología y por la socialdemocracia", sostiene Juan Diego, quien desde niño trabaja en el partido como guía electoral y no esconde su pretensión de, algún día, probablemente con el respaldo de Eduardo, llegar a ocupar una curul (Mata, 2014).

Antes de proceder al análisis de contenido de las noticias relacionadas con la implementación de educación sexual en los colegios públicos, se desea dejar claro una característica que diferencia - de forma drástica- el contenido de estas noticias con el contenido de otras noticias analizadas en relación con las personas jóvenes costarricenses: los jóvenes no son actores principales ni activos en el contenido de la noticia. Así, más que participantes, las personas jóvenes son objeto de discusión por parte de otros actores, principalmente la Iglesia católica y el Ministerio de Educación Pública (MEP).

En cuanto a las clases de educación sexual, este medio informa que existe un conflicto entre la autoridades políticas y los grupos religiosos sobre qué se le debe enseñar a las personas jóvenes. De esta manera, La Nación informa que las autoridades católicas y evangélicas se oponen a los contenidos que se imparten en los cursos de educación sexual; asimismo, consideran que la alta asistencia a estas clases se debe a que el MEP "engaña" a los padres y madres de familia para que ¿envíen? a los y las estudiantes: "Entre tanto, autoridades evangélicas y católicas atribuyen esta masiva asistencia a la 'desinformación' que tienen las familias sobre los temas incluidos en el programa, y a las 'falacias que vendió' el MEP” (Villegas, 2012).

Además, este medio indica que se impusieron "miles" de recursos de amparo y administrativos con el propósito de poner freno a estos programas, no obstante, todos fueron rechazados. El único pronunciamiento importante por parte de la Sala Constitucional fue el indicar que los padres y madres podrían decidir si sus hijos e hijas recibieran el curso (Ross y Morales, 2012; Ross, 2013). Sobre este punto, el medio reproduce una declaración de Laura 
Chinchilla, en ese momento presidenta de la República, la cual trata de tomar una actitud conciliatoria ante las posiciones de los distintos actores:

"Siempre lo he dicho: la educación principal tiene que originarse en las familias, pero el Estado también tiene la obligación de complementar cuando existen vacíos. Pero también es cierto que las Iglesias tienen la posibilidad de generar complementos a través de la formación que ellas proveen a nivel de la comunidad", indicó Chinchilla (Ross y Morales, 2012).

La anterior situación lleva a las autoridades de la Iglesia católica a expresar que, si bien mantienen críticas al contenido de este plan de estudio, es decisión de los padres y madres el permitir o no que sus hijos e hijas asistan a dichas clases (Murillo, 2012). Por otra parte, La Nación indica que autoridades de iglesias evangélicas denuncian que los y las jóvenes que deciden no asistir a los cursos de educación sexual sufren discriminación por parte de otros estudiantes y el cuerpo docente (Ross, 2013). En contraposición, La Nación recurre a declaraciones de estudiantes para mostrar lo positivo que ha sido este curso para ellos:

"En la clase de Sexualidad y la de Ciencias podemos preguntar, porque hay confianza para hacerlo, a diferencia de antes. Yo aprendí que no debo ser manipulada por un hombre, ni apartar mis amistades si alguien (novio) me lo pide", expresó la alumna Reychel Mendoza.

Su compañero, Danny Matarrita, dijo que aprendieron que todos deben ayudar con los oficios domésticos en las casas.

Válery Picado dijo que algunos compañeros ya no la regañan cuando no juega bien voleibol (Villegas, 2012),

La narrativa de La Nación lo que demuestra es el conflicto de posiciones respecto a la educación sexual que deben tener las personas jóvenes y sobre quién es el encargado de definirla: las iglesias, las familias o el Estado. Asimismo, si bien parece que el medio parte de la idea de que es beneficioso para la población joven recibir una adecuada educación sexual, las personas jóvenes están excluidas totalmente de la discusión. De esta manera, si bien pueden expresar lo útil que les ha resultado esta formación, no pueden 
opinar sobre el tipo de educación sexual que les gustaría tener, ni acerca de la posición de los otros actores identificados en el conflicto.

De esta forma, en la narrativa del medio, las personas jóvenes, al menos en este tema, se presentan como agentes pasivos que reciben la instrucción de figuras de autoridad. Además, este parece ser el modelo correcto para el medio. Por lo tanto, para La Nación las personas jóvenes son importantes, siempre y cuando estén en una posición de subordinación ante las personas adultas, las cuales, según entiende el medio, son las que conocen qué necesitan y qué deben hacer los y las jóvenes.

\section{Consideraciones finales}

Tras la revisión de noticias publicadas por La Nación, en relación con cuatro coyunturas distintas en las cuales se puede apreciar el discurso del medio sobre las personas jóvenes, se puede concluir que existen dos narrativas claramente diferenciadas. De esta manera, se retoma la hipótesis expresada al inicio del artículo: La imagen que proyecta el periódico La Nación sobre las personas jóvenes depende del espacio en que estos participan, así como de la valoración que el propio medio realiza sobre estos espacios, a partir de una postura de adultocentrismo político respecto a la participación de las persona jóvenes; de tal manera que visualizará como positivas las acciones de personas jóvenes en espacios controlados o reglamentados por personas adultas y como negativas las acciones de personas jóvenes en espacios donde no son directamente "supervisadas" por adultos.

Así, La Nación resalta como negativas las acciones de las personas jóvenes en espacios no formales, en los cuales no hay ningún tipo de organización o control por parte de estructuras o instituciones que considere legítimas, es decir, dirigidas por personas adultas (no jóvenes). Tal es el caso de la participación de los y las jóvenes en movimientos sociales y acciones de protesta, pues las noticias publicadas por este medio resaltan los daños que ocasionan, a pesar de que estos sean realizados por un pequeño grupo de manifestantes. Al mismo tiempo, el medio ignora los argumentos y motivos que llevan a las personas jóvenes a manifestarse. De esta manera, la imagen que se proyecta a la opinión pública es de un desorden y conflicto, por lo cual se justifica la necesidad de que una autoridad deba intervenir y corregir el comportamiento transgresor de las personas jóvenes, aunque para ello deba realizar acciones violentas contra este grupo. Esto refuerza lo sugerido por Vásquez (2011, p.11) acerca de que la narrativa de los medios tiene la tendencia de presentar a los jóvenes como sujetos amenazantes.

Caso contrario ocurre con las personas jóvenes cuyo accionar se da dentro del marco de espacios institucionalizados. Incluso, en este caso, La Nación trata de desmentir o alejar a la opinión pública de imágenes negativas que 
puedan tener sobre este grupo de jóvenes. Por ejemplo, en cuanto a los jóvenes que participan en partidos políticos, el medio trata de mostrar que estos no son solamente "pegabanderas", sino que realizan otras actividades dentro de las agrupaciones políticas y, si llevan a cabo ese tipo de actividades, estas no se visualizan como algo negativo, sino como parte de una serie de acciones necesarias para el funcionamiento de los partidos políticos.

Lo anterior es consecuente con resultados de otras investigaciones, las cuales muestran que en el discurso de La Nación se tiende a presentar como positivo que la ciudadanía recurra a espacios formales (tribunales, mesas de negociación, procesos electorales, etc.), sobre los espacios informales (manifestaciones, huelgas, etc.), para presentar sus demandas y tratar de incidir en el espacio político (Díaz, 2012b y 2014). Por lo tanto, el discurso de La Nación sobre la participación de las personas jóvenes no solo responde a una visión adultocentrista de la política, sino también a una estrategia narrativa más amplia que mantiene el medio, en la cual trata de posicionar ante la opinión pública la idea de que las actuaciones ciudadanas "correctas" son aquellas que transcurren en espacios institucionalizados bajo la supervisión o control de autoridades políticas, jurídicas o institucionales.

En el caso de los jóvenes y la educación sexual, el problema no radica en qué hacen los jóvenes sino en quién es el responsable de decidir por ellos. Con esto se refuerza la idea de que el comportamiento correcto de las personas jóvenes es aquel que se encuentra definido por una figura adulta, la cual tiene la capacidad de decidir qué es lo más conveniente para esta población. Aquí destaca otro punto importante en la narrativa de La Nación: las personas jóvenes que tienen un accionar visualizado como positivo son aquellas cuyas acciones pueden considerarse como pasivas; es decir, aquellas que responden al mandato de una figura de autoridad. Por otra parte, las personas jóvenes que actúan por su cuenta, sin ningún tipo de supervisión de una figura de autoridad (es decir, que son activas), presentan un accionar valorado como negativo por el medio. Por lo tanto, queda visualizado así que el discurso informativo de La Nación mantiene una línea adultocentrista, donde lo correcto es que las personas jóvenes actúen y estén bajo la supervisión de una figura adulta, la cual pueda constatar que las acciones que realizan sean correctas; ya que cuando esto no ocurre, las acciones de las personas jóvenes son negativas.

Si lo anterior se considera a la luz de que la pasividad de la población costarricense es un componente de la tendencia autoritaria presente en el país (Mora, Solís y Soto, 2014), se puede observar por lo tanto que el discurso de La Nación es un reflejo -aunque sea parcial- de lo que sucede en la sociedad costarricense a mediados de la segunda década del siglo XXI. De esta manera, el adultocentrismo se presenta tanto en el discurso del medio como en la sociedad costarricense, pues forma parte de esa tendencia 
autoritaria presente de manera general en la población, donde la pasividad de los habitantes, en este caso específico de las personas jóvenes, se ve casi como una "virtud". Esto se debe a que es un elemento indispensable mantener y reproducir este modelo autoritario presente en Costa Rica.

Como se indicó al inicio, es incorrecto suponer que las personas lectoras de las noticias de La Nación tomen el discurso expresado por este medio sobre las personas jóvenes y lo adopten como propio sin ningún tipo de crítica o procesamiento. Sin embargo, se debe considerar la información proporcionada por los medios como una base importante para la construcción de la opinión pública y de las percepciones de las personas sobre distintos temas. Tal y como se señaló al inicio del presente artículo, los "medios pueden imponer su propia lógica al ensamblar materiales en una serie de maneras, incluyéndose el énfasis de ciertos comportamientos y personas y estereotiparlas" (Shoemaker y Reese, 1994, p. 38). Este sería el caso de la narrativa que se construye en relación con las personas jóvenes que se manifiestan en espacios fuera del control de personas "adultas". El ejemplo más claro presentado en este artículo es el caso de los "anarquistas", quienes son presentados básicamente como un arquetipo del comportamiento indebido al que recurren las y los jóvenes.

Asimismo, como establece Luhmann (2007), la narrativa de los medios es en mayor o menor grado- un reflejo de las opiniones e intereses de la sociedad a la que van dirigida. Por lo tanto, el discurso del periódico La Nación es un indicador del adultocentrismo presente en Costa Rica y ayuda a comprender la posición que tienen las personas jóvenes en los imaginarios de la población costarricense, así como los parámetros sobre los que la mayoría de la sociedad interpreta y evalúa el comportamiento de las y los jóvenes.

\section{Bibliografía}

Arguedas, C. y Láscares, C. (2013, mayo 3) Cinco de los 10 detenidos el $1^{\circ}$ de mayo por los disturbios en San José solo recibirían una multa. La Nación. Recuperado de http://www.nacion.com/sucesos/detenidosdisturbios-San-Jose-recibirian_0_1339266130.html

Barrantes, A. y Arguedas, C. (2013, mayo 2) Golpes fueron el cierre de la fiesta de los trabajadores. La Nación. Recuperado de http://www.nacion.com/nacional/comunidades/Golpes-cierre-fiestatrabajadores_0_1339066164.html 
Bustos Mora, G. (2011) La mirada mediática hacia "Tierra Dominicana": una aproximación desde el Análisis Crítico del Discurso (ACD) Revista Rupturas 1(1), 108-124. Disponible en:http://investiga.uned.ac.cr/

Carballo Cháves, P. E. (2009) El discurso mediático sobre el sistema educativo público costarricense. Estudio y análisis ideológico/discursivo del diario La Nación. Mayo del 2007 - Abril del 2008 Tesis para optar por el grado de Licenciatura en Sociología. Universidad de Costa Rica, San José.

Casimigilia, G. y Tusón, A. (1999) Las cosas del decir. Barcelona: Editorial Ariel.

Cuesta, B. M. (2012, octubre 11) Ministerio de Seguridad denuncia a 11 sujetos por disturbios en Asamblea Legislativa. La Nación. Recuperado de :http://www.nacion.com/sucesos/

Díaz González, J. A. (2012a) Análisis político del discurso informativo de la prensa escrita sobre los movimientos sociales (FASE II). Informe final de investigación. Heredia: Instituto de Estudios Sociales en Población, UNA.

Díaz González, J. A (2012b). La prensa escrita ante el referéndum acerca de la Unión de personas del mismo sexo (2010). Revista Rupturas 2(2), 294-326

Díaz González, J. A.(2013) De caminatas a los juzgados: Análisis del discurso de los medios de prensa sobre el proyecto minero Crucitas.Revista Polis, 36. Recuperado de:http://polis.revues.org/

Díaz González, J. A. (2014) De caminatas a los juzgados: Análisis del discurso de los medios de prensa sobre el proyecto minero Crucitas. Revista Polis, 36.

Díaz, L. E. (2012, septiembre 1) Editoriales claman por freno a ley de fotocopiado. La Nación. Recuperado de http://www.nacion.com/nacional/comunidades/Editoriales-claman-frenoleyfotocopiado_0_1290470990.html

Herrera, L. M. (2012, mayo 1) 'Anarquistas' lanzan botellas y piedras frente al Congreso. La Nación Recuperado de http://www.nacion.com/nacional/comunidades/Anarquistas-lanzanbotellas-piedras-Congreso_0_1265873426.html

Lara, J. F. (2009, mayo 2) Agresivo grupo silenció discurso de sindicalistas. La Nación. Recuperado de http://www.nacion.com/nacional/Agresivogrupo-silencio-discurso-sindicalistas_0_1046895360.html 
Láscares, C. (2013, mayo 2) Últimos dos manifestantes quedaron esta noche en libertad en Goicochea. La Nación. Recuperado de http://www.nacion.com/sucesos/Ultimos-manifestantes-quedaronlibertad-Goicoechea_0_1339066208.html

Luhmann, N. (2007) La realidad de los medios de masas. Barcelona: Editorial Anthropos.

Mata, E. y Altamirano, P. (2012, octubre 9) Manifestantes se dispersan de las afueras de la Asamblea Legislativa. La Nación. Recuperado de http://www.nacion.com/nacional/comunidades/Manifestantes-dispersanafueras-Asamblea-Legislativa_0_1298070300.html

Mata Blanco, A. (2014, enero 19) El rostro joven de la política. La Nación. Recuperado de http://www.nacion.com/ocio/revista-dominical/Juventudcolor-politico_0_1391460861.html

Mata Blanco, A. (2014, enero 29) Juventud tendrá poca presencia en el Congreso. La Nación. Recuperado de http://www.nacion.com/nacional/elecciones2014/Juventud-pocapresencia-Congreso_0_1393460685.html

McQuail, D. (1996) Introducción a la teoría de la comunicación de masas (2ª ed.). México, D.F.: Paidós Comunicación.

Mora, S.; Solís, M. y Soto, L. D. (2014). Entre el apoyo a la democracia y el autoritarismo en Costa Rica. Anuario de Estudios Centroamericanos, 40. En prensa.

Murillo Medrano, J. y Vergara Heidke, A. (2004) Una propuesta de análisis textual a partir de los postulados del análisis crítico del discurso. Revista de Filología y Lingüística de la Universidad de Costa Rica, $30(1)$,

Murillo, A. (2010) Costa Rica: La tentación contenida. En Rincón, O. (Ed.) ¿Por qué nos odian tanto? Estado y medios de comunicación en América Latina. Bogotá: Centro de competencia para la comunicación en América Latina Friederich Ebert Stiftung.

Murillo, A. (2012, octubre 18) La incertidumbre se prolonga en la calle de las fotocopias. La Nación. Recuperado de http://www.nacion.com/nacional/politica/incertidumbre-prolonga-callefotocopias_0_1299870050.html

Murillo, A. (2012, noviembre 15) Obispos dejan a conciencia de papás mandar sus hijos a educación sexual. La Nación. Recuperado de 
http://www.nacion.com/nacional/politica/Obispos-conciencia-mandareducacion-sexual_0_1305469542.html

Oviedo, E. y Cerdas, D. (2012, octubre 9) Manifestantes y Policías chocan en las afueras de la Asamblea Legislativa. La Nación. Recuperado de http://www.nacion.com/nacional/politica/Manifestantesy-policiasafueras-Asamblea-Legislativa_0_1298070306.html

Robles, F. y Voorend, K. (2012) Los dueños de la palabra en un contexto de reforma neoliberal. Revista Rupturas, 1(2).

Ross, A. y Morales, C. (2012, agosto 31) Chinchilla dejaría a hijo ir a clases de educación sexual. La Nación. Recuperado de http://www.nacion.com/nacional/comunidades/Chinchilla-dejaria-claseseducacion-sexual_0_1290271036.html

Ross, A. (2013, mayo 10) 98\% de colegiales llevan clases de educación sexual. La Nación. Recuperado de http://www.nacion.com/nacional/comunidades/colegiales-llevan-claseseducacion-sexual_0_1340665927.html

Shoemaker, P. J. y Reese, S. D. (1994) La mediatización del mensaje. Teorías de las influencias en el contenido de los medios de comunicación (1ª ed.). México, D.F.: Editorial Diana.

Sibaja Quesada, G. (2009) Imaginario político de los jóvenes costarricenses: una exploración de sus miedos y deseos. San José: FLACSO.

UNICEF (2013) Superando el adultocentrismo. Santiago: Fondo de las Naciones Unidas para la Infancia.

van Dijk, T. (1999) Context models in discourse processing. En Van Oostendorp, $\mathrm{H}$. et al. (Eds.) The construction of mental representations during reading (123-148). Mahwah, NJ: Lawrence Erlbaum Associates.

van Dijk, T. (2000) El discurso como interacción en la sociedad. En van Djik, T. (Comp.) El discurso como interacción social. Estudios sobre el discurso: Una introducción multidisciplinaria (Vol II). Barcelona: Editorial Gedisa.

van Dijk, T. (2005) Ideologías y análisis del discurso. Utopía y Praxis latinoamericana, 10(29), 9-26. Maracaibo: Universidad del Zulia.

Vásquez, J. D. (2011) Aproximaciones críticas a las narrativas periodísticas sobre personas jóvenes en Costa Rica. En Brenes, M. et al. (Coords.) Miradas que marcan. Análisis crítico de las narrativas de los y las jóvenes en la prensa. San José: Universidad de la Salle. 
Villalobos, C. (2000) Marcas de subjetividad en el discurso informativo: una propuesta de análisis. En Vega, P. (Comp.) Comunicación, política e identidad. San José: Editorial de la Universidad de Costa Rica.

Villegas, J. (2012, noviembre 3) Iglesias pierden lucha contra educación sexual en colegios. La Nación. Recuperado de http://www.nacion.com/nacional/comunidades/lglesias-pierdeneducacion-sexual-colegios_0_1303069692.html 